\title{
A REFORMA DO CENTRO DE ATENDIMENTO AO PÚBLICO: UMA INTERVENÇÃO NO AMBIENTE CONSTRUÍDO FUNDAMENTADA EM ANÁLISE MACROERGONOMICA
}

\author{
COSTA, Ana Paula Lima (1); \\ MELO, Paula Quintas de (2) \\ (1) Ministério da Fazenda, Doutora em Design \\ e-mail: aplimacosta@gmail.com \\ (2) Federação das Indústrias do Estado do Rio de Janeiro, Mestre em Ergonomia \\ e-mail: paulinhaqm@gmail.com
}

\begin{abstract}
RESUMO
Este artigo descreve a ação ergonômica que fundamentou uma intervenção no ambiente construído do setor de atendimento ao público de uma empresa pública. A Análise Macroergonômica do Trabalho foi empregada como ferramenta para investigar o uso do espaço e gerar proposições de soluções. Foram realizadas entrevistas e questionários com os usuários para identificação dos itens de demanda ergonômica e priorização dos problemas. Os dados geraram ações ergonômicas direcionadas a intervenções no ambiente físico, e fundamentaram o projeto arquitetônico, que elaborou o leiaute dos espaços de modo a atender às determinações organizacionais e adequar os ambientes às necessidades dos usuários.
\end{abstract}

Palavras chave: ergonomia organizacional, empresa pública, projeto de arquitetura.

\begin{abstract}
This article describes the ergonomic action that grounded an intervention in the built environment of the public service sector of a public company. Macroergonomic Analysis of Work was used as a tool to investigate the use of space and to generate propositions of solutions. Interviews and questionnaires were carried out with the users to identify ergonomic demand items and prioritize the problems. The data generated ergonomic actions directed to interventions in the physical environment, and based the architectural design, which distributed the spaces in order to meet the organizational determinations and adapt the environments to the users' needs.
\end{abstract}

Keywords: organizational ergonomics, public company, architecture project.

\section{INTRODUÇÃO}

O presente estudo teve início a partir da solicitação de uma empresa pública de reformular o espaço físico do setor de atendimento ao público. Contudo, o apelo dos trabalhadores do local por melhores condições de trabalho alertou que era preciso investigar as causas das insatisfações dos usuários, sendo o ponto de partida para realizar a intervenção ergonômica, de modo a propor soluções integradas para o ambiente físico que atendessem às necessidades dos usuários do ambiente. 


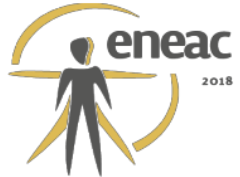

O centro de atendimento ao público (denominado contribuinte) foi implantado nessa empresa pública para proporcionar ao contribuinte um local adequado para receber atendimento presencial, objetivando melhorar a produtividade da empresa e os serviços prestados ao público (BRASIL, 1993). De acordo com Ferreira (2000), a simplicidade do serviço de atendimento ao público aparenta ser simples, mas trata-se de uma complexa atividade social mediadora, que coloca em cena a interação de diferentes sujeitos em um contexto específico, visando responder a necessidades diversas, no qual o serviço de atendimento ao público é um processo resultante da sinergia de diferentes variáveis: 0 comportamento do público, a conduta dos funcionários, a organização do trabalho e as condições físicas, ambientais e instrumentais.

Considerando-se que o ambiente físico de uma empresa é estruturado para atender às determinações organizacionais, a inadequação do ambiente aos procedimentos dos serviços indica que existe uma discrepância entre a estrutura organizacional e a utilização do espaço físico, o que leva ao não atendimento às necessidades dos usuários. Como conseqüência, há redução da qualidade dos serviços prestados pela instituição (FERREIRA e MENDES, 2001).

Tendo em vista que a ergonomia é uma disciplina orientada para uma abordagem sistêmica de todos os aspectos da atividade humana, abordando de forma holística os aspectos físicos, cognitivos, sociais, organizacionais e ambientais, a ergonomia direciona-se para o entendimento das interações entre seres humanos e outros sistemas; dessa forma, fornece princípios teóricos e métodos para projetar e otimizar o bem-estar humano e o desempenho geral desse sistema (IEA, 2018). Com isso, nesse estudo a abordagem ergonômica foi empregada para investigar as causas e possíveis soluções para as disfunções das ações ocorridas no ambiente.

Segundo lida (2005), os projetos de espaços com enfoque ergonômico partem das necessidades humanas, das tarefas e das organizações sociais. Considerando-se que a implantação de modificações em uma organização requer equilíbrio entre os subsistemas ambientais, organizacionais e humanos, de forma mais adequada para atingir a otimização do sistema global, empregou-se a abordagem macroergonômica, identificada como a aplicação da ergonomia no nível macro, ou seja, em toda organização que abriga a atividade. Nessa intervenção, a ergonomia passa a participar do projeto e gerenciamento de ações, atuando na direção da empresa, refletindo no nível de emprego e organização da produção, podendo resultar em melhorias de maior alcance do que em abordagem micro, ou seja, isoladamente no posto de trabalho.

\section{METODOLOGIA}

A Análise Macroergonômica do Trabalho - AMT (GUIMARÃES, 2006) é um método de ação ergonômica com abordagem participativa que focaliza o ser humano, o processo de trabalho, a organização, o ambiente e a máquina integrados em um sistema mais amplo. Neste método, os trabalhadores são envolvidos nas decisões sobre seus trabalhos e atividades, e são encorajados a tomar decisões em nível gerencial, se envolvendo na organização.

A metodologia do design macroergonômico propõe o uso de ferramentas, tais como entrevistas e questionários, para identificação dos itens de demanda ergonômica, envolvendo as necessidades no ambiente de trabalho, bem como análises estatísticas e instrumentos de decisão na priorização dos itens relacionados nas entrevistas e nos questionários. De acordo com Guimarães (2004), o processo participativo é um dos mais importantes dentre os métodos adaptados para implantação da ergonomia, no qual o 


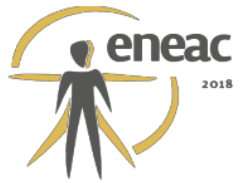

envolvimento dos indivíduos reduz a margem de erros de concepção e garante que o novo sistema implantado tenha melhor aceitação por parte dos trabalhadores.

$\mathrm{Na}$ AMT são considerados os subsistemas de sistemas sociotécnico, social (humano), técnico (tecnológico), projeto do trabalho (organização do trabalho) e ambiente externo (GUIMARÃES, 1999). Desta forma, a AMT enfatiza a interação entre os contextos organizacional e psicossocial de um sistema, com vistas à melhor adequação de processos e concepção de novos sistemas.

A AMT é aplicada em seis etapas (GUIMARÃES, 1999):

- Lançamento do projeto;

- Levantamento das condições de ambiente físico, do posto de trabalho, dos fatores organizacionais e de conteúdo do trabalho;

- Priorização dos problemas a serem aprofundados;

- Diagnóstico e proposição de soluções;

- Validação, quando são verificadas as modificações propostas;

- Relatório final de detalhamento de projeto.

\section{ESTUDO DE CASO}

A ação ergonômica no ambiente construído foi originada a partir da solicitação da empresa de realizar uma reforma arquitetônica no ambiente físico do setor de atendimento ao público; o objetivo principal da intervenção era melhorar as condições de trabalho e de funcionamento do ambiente construído.

A partir de reuniões com os dirigentes da instituição, viu-se a necessidade de realizar um estudo mais profundo no ambiente construído, de maneira que englobasse as pessoas envolvidas na concepção do espaço e na organização do trabalho, de modo a conhecer as causas dos problemas e passasse a fornecer soluções para saná-los. Dessa forma, decidiuse por realizar uma ação macroergonômica, de modo a utilizar uma abordagem participativa que focalizasse o ser humano, o processo de trabalho, a organização, e o ambiente.

\subsection{Lançamento do Projeto}

O projeto da intervenção macroergonômica foi apresentado aos dirigentes da repartição e aos trabalhadores do setor de atendimento, explicando que a intervenção a ser realizada no ambiente de trabalho visava ao melhoramento das condições de trabalho, e por isso, afetaria o trabalho de todos os envolvidos. Na ocasião foi solicitada a colaboração voluntária de todos, visto que a participação na pesquisa não era obrigatória.

\subsection{Levantamento das condições de ambiente físico, do posto de trabalho, dos fatores organizacionais e de conteúdo do trabalho.}

Inicialmente foi realizada uma observação indireta com registros fotográficos das atividades de trabalho, seguida de pesquisa sobre o funcionamento da empresa.

a. Condições de ambiente físico 


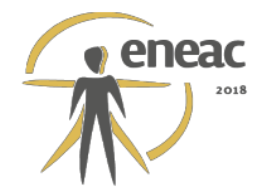

O prédio no qual o local de atendimento ao público estava situado foi construído na década de 50 do século vinte. A edificação possuia $6.718,71 \mathrm{~m}^{2}$ de área construída distribuídas em sete pavimentos. $\mathrm{O}$ ambiente de atendimento ao público localizava-se no pavimento térreo, ocupando área de $645,25 \mathrm{~m}^{2}$, composto de sala de espera, salas de atendimento e salas de apoio administrativo, conforme planta baixa (Figura 1).

Figura 1 - Planta baixa do ambiente de atendimento ao público

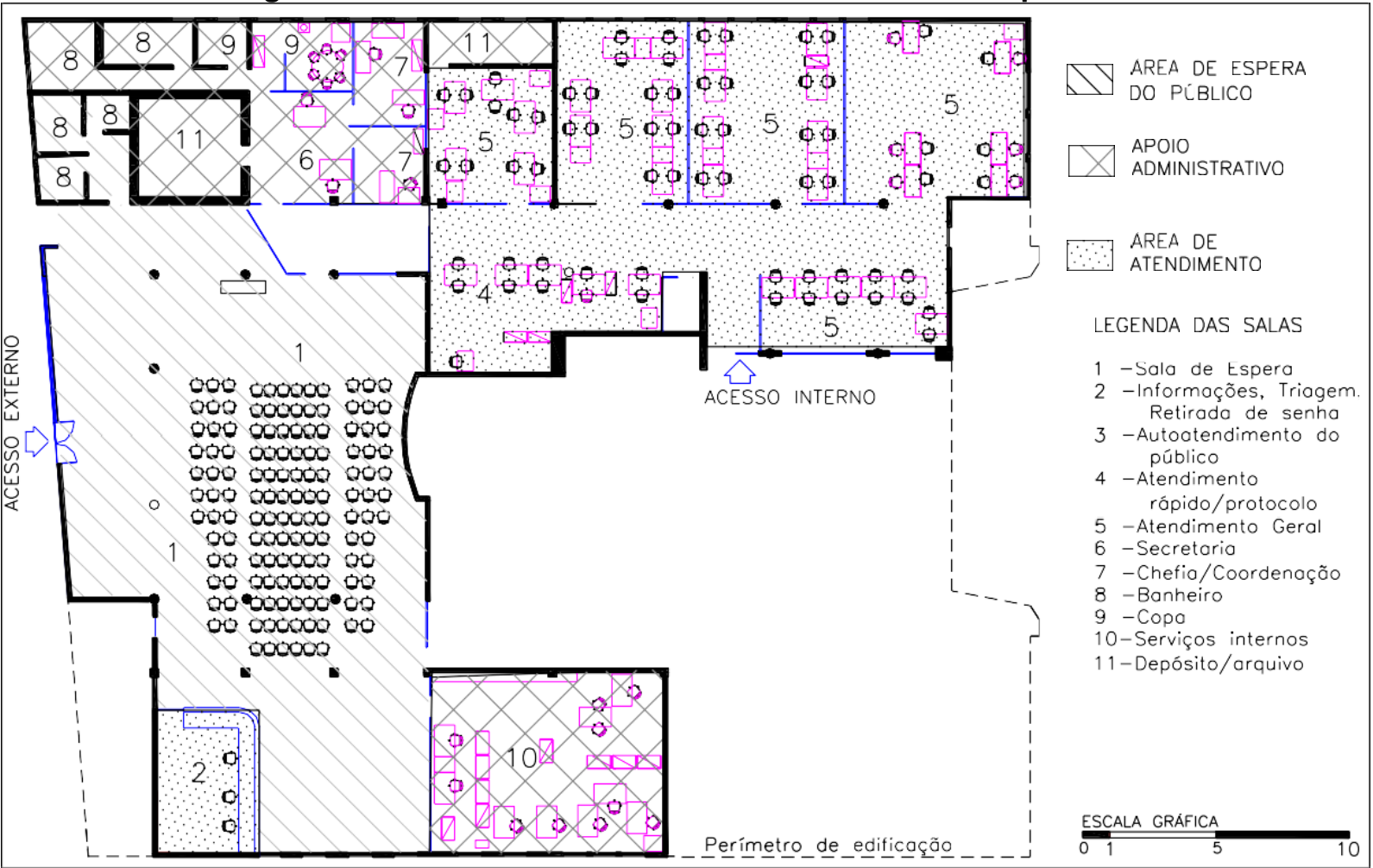

Fonte: Ana Paula Costa

\section{b. Fatores Organizacionais}

Até o ano de 1993, a repartição pública na qual o setor de atendimento está situado estruturava-se em sistemas especializados por área técnica, nos quais as atividades internas e de atendimento ao público externo eram executadas sem uniformização de procedimentos e sem que houvesse especialização para cada tarefa. Consequentemente, não era reservado ao atendimento ao público um local próprio e adequado (CORBARI, 2005).

Objetivando proporcionar ao público um atendimento rápido, conclusivo, uniformizado e concentrado em um único local, foram criadas diretrizes para implantação do modelo de atendimento denominado "Central de Atendimento ao Contribuinte" (BRASIL, 1993), a fim de melhorar a produtividade e os serviços prestados ao público, visando o conforto e a satisfação do cliente.

\section{c. Conteúdo e Organização do Trabalho}

No ano de 2006, quando foi iniciada a intervenção ergonômica do ambiente, estavam lotados cinqüenta e sete servidores públicos, dos quais, quarenta e um realizavam o serviço de atendimento ao público, e dezesseis atuavam em atividades internas. 


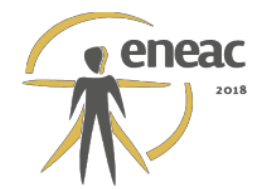

O setor de atendimento da repartição pública tinha como tarefas verificar e receber documentação do público e fornecer orientações tributárias. Cada tarefa realizada no local era denominada "atendimento". Os serviços prestados eram divididos de acordo com os assuntos a serem tratados, de modo que cada atendente se dedicava a apenas um tipo específico de assunto. Os atendimentos prestados eram organizados através um sistema de gerenciamento eletrônico de filas.

A jornada de trabalho dos atendentes era de seis horas corridas, com intervalo de quinze minutos. Nesse espaço de tempo, em média eram realizados mil e seiscentos atendimentos a cerca de oitocentas pessoas. Cada trabalhador atendia cerca de quarenta e cinco pessoas, empregando um tempo médio de oito minutos para cada atendimento; contudo, em alguns casos os atendimentos se estendiam por três horas.

\section{d. Biomecânico / Posto de Trabalho}

Cada atendente trabalhava em uma unidade individualizada, denominado posto de trabalho, composto por uma mesa de trabalho com gavetas, uma cadeira para uso próprio, uma cadeira para acomodar o visitante (Figura 2). A tipologia do mobiliário era diversificada. A superfície de trabalho era insuficiente para acomodar os equipamentos de informática de uso individual (monitor, CPU, teclado e mouse) e para a colocação de material de consulta e de uso dos visitantes. As impressoras eram compartilhadas entre os trabalhadores e se localizavam em mesas que dividiam os postos de trabalho (Figura 3). Não existiam assentos adequados para portadores de necessidades especiais. Não havia tratamento isolamento acústico para proporcionar conforto auditivo no local durante o atendimento. Devido a registros diários de agressões verbais e físicas aos atendentes por parte do público, no local era realizada vigilância presencial intensiva e ostensiva.

Figura 2 (à esquerda) - Vista lateral do posto de trabalho de atendimento Figura 3 (à direita) - Vista do público sendo atendido. Entre cada dois postos de trabalho, é disponibilizada uma impressora.
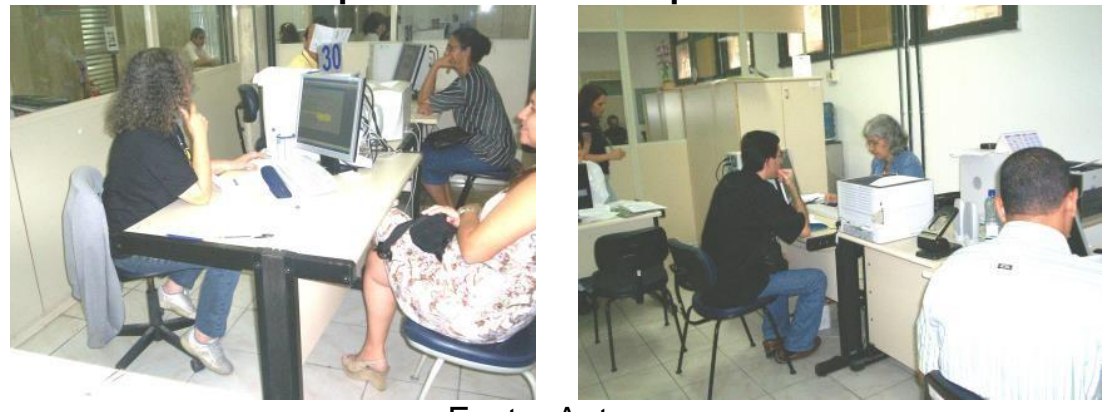

Fonte: Autoras

\subsection{Priorização dos Problemas}

Para priorização dos problemas foi necessária a efetiva contribuição dos usuários do ambiente com as suas impressões sobre o seu local de trabalho. Para coletar as informações, foram realizadas entrevistas abertas e questionários com os trabalhadores.

$\mathrm{Na}$ primeira fase, treze trabalhadores se disponibilizaram para participar de entrevistas desestruturadas, aos quais era solicitado que falassem livremente sobre seu trabalho. A pergunta foi aplicada de forma a obter respostas abertas por meio do método dedutivo.

A tabulação das respostas ocorreu através de um sistema de valoração das questões abordadas, nas quais as primeiras impressões relatadas receberam uma pontuação maior 
do que as citadas posteriormente. O sistema de pontuação decrescente partiu do princípio que os primeiros itens citados seriam os que afetariam em maior profundidade os usuários, tendo em vista que foram inicialmente lembradas por eles; dessa maneira, a pontuação para cada resposta tornou-se variável entre os entrevistados, de acordo com a ordem de citação de cada um deles (GUIMARÃES, 2002).

Para tabular e organizar de acordo com a ordem de prioridade elencada pelo entrevistado, foi utilizada a fórmula $1 / x$, sendo " $x$ " igual à ordem de citação, ou seja, nos itens citados primeiramente, a incognita " $x$ " recebeu o valor "1", no qual a resposta teria peso igual a 1, ou seja, $1 / 1=1$; quando o item eram o segundo a ser citado, o peso da resposta era divido por dois, $1 / 2=0,5$ e assim em sequencia. Através desta fórmula, foram calculados os pesos das respostas dos funcionários e tabulados para análise (ASSIS et al, 2015).

No total, os trabalhadores relataram sessenta e quatro questões sobre o trabalho. As questões mais citadas foram: solicitações para melhorar o mobiliário, relatos de problemas físicos e mentais resultantes do exercício da profissão, conscientização da importância do trabalho realizado para a empresa, sugestões para melhora do leiaute e queixas do barulho do ambiente.

Ao somarmos os pontos obtidos em cada entrevistado, as citações que receberam maior pontuação foram consideradas como demandas ergonômicas prioritárias. As demandas foram categorizadas em Ambiente Físico (44\% das respostas), Biomecânica/posto de trabalho (19\% das respostas), Empresa (18\% das respostas), Organização do trabalho (9\% das respostas), Risco do trabalho (5\% das respostas), e Clientes (público atendido no local) (5\% das respostas).

Em relação à categoria Ambiente Físico, as demandas cadastradas foram: mobiliário sem espaço suficiente; solicitação de melhoria no leiaute do ambiente; reclamação de ruído no local resultante do maquinário do sistema de refrigeração e pela falta de isolamento acústico entre os postos de atendimento; solicitação para melhorar a iluminação; queixas pelo espaço insuficiente para acomodar a quantidade de pessoas que utilizavam o espaço; solicitações para instalação de vidro de proteção para evitar o contato direto com o público, melhorar as instalações prediais em geral e instalar de placas de sinalização. De um modo geral, a percepção dos trabalhadores era que o ambiente os "dificultava a concentração durante o trabalho".

Em relação à categoria Biomecânica, os itens de demanda ergonômica que receberam maiores pontuação foram: reclamação de lesões supostamente causadas pelas posturas adotadas para se adaptar ao mobiliário, e estresse mental devido à realização do serviço. Foram solicitados o exercício de ginástica laboral e o acompanhamento psicológico aos atendentes.

Em relação à categoria Empresa, os atendentes reconheciam que seu trabalho era importante para a empresa, mas que suas reivindicações não eram atendidas pela administração. Houve solicitações para participação de cursos de atualização e treinamentos.

Em relação à categoria Organização do Trabalho, os trabalhadores relataram que o número de atendentes era insuficiente para realizar o serviço, e que deveria ser realizado um serviço de orientação ao público em momento anterior à realização do atendimento. Apesar de relatarem que nem sempre cumpriam o intervalo de descanso, os trabalhadores gostavam da jornada de seis horas diárias do serviço que realizavam, mas tinham a convicção que poderiam realizar de melhor forma se houvesse mais engajamento por conta da administração.

Em relação à categoria de Risco de Trabalho, o item de demanda ergonômica que recebeu maior pontuação foi a agressividade do público, em parte devido à natureza do assunto que vem a ser tratado no local, e em parte devido ao tempo de espera de duas horas, em média, 


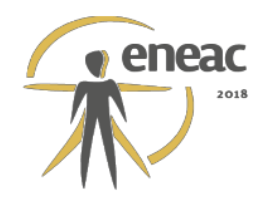

considerado longo e desgastante pelo público; para isso, os trabalhadores solicitam a presença mais efetiva de vigilância ostensiva presencial no local. Também foi relado que, devido à proximidade física dos atendentes com uma grande quantidade de pessoas em um ambiente fechado, os atendentes se sentiam mais vulneráveis e expostos a doenças infectocontagiosas.

Em relação à categoria Clientes, foram agrupadas as questões citadas pelos trabalhadores relativas ao público que era atendido no local. Os itens de demanda ergonômica que receberam maior pontuação foram que os atendentes achavam que eram dispensados poucos cuidados ao público, tais como disponibilização de informações sobre 0 funcionamento da repartição pública, e que era excessivo o tempo de espera para o publico ser atendido. Por essa razão, a sala de espera permanecia com grande concentração de pessoas (Figuras 4 e 5). Devido aos muitos casos de cidadãos apresentarem problemas médicos durante o atendimento, foi sugestionado pelos trabalhadores que houvesse no local um posto de assistência médica de urgência.

Figura 4 (à esquerda) - Área de espera do público, com a tela de chamada de senhas ao fundo Figura 5 (à direita) - Área de espera do público, vista do acesso à sala de atendimento

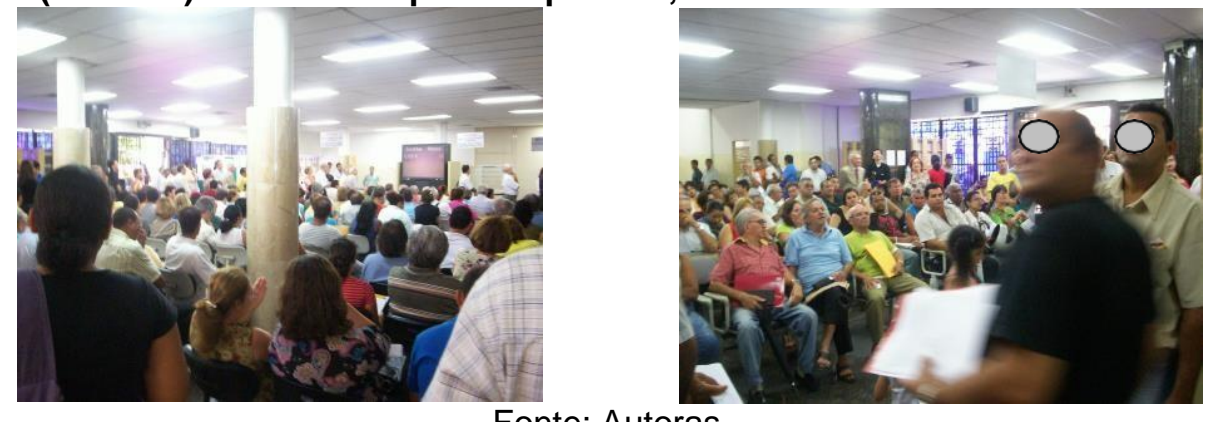

Fonte: Autoras

$\mathrm{Na}$ segunda fase de conhecimento da percepção dos trabalhadores, foi aplicado um questionário em vinte e um atendentes, no qual se relacionavam questões quanto à satisfação no ambiente de trabalho e quanto à saúde dos entrevistados.

Os resultados relevaram que $100 \%$ dos entrevistados achavam que seu trabalho envolvia muita responsabilidade; $89 \%$ dos entrevistados achavam que era exigido muito esforço mental; $89 \%$ dos entrevistados achavam que a sua atividade envolvia muito risco; $89 \%$ dos entrevistados não achavam que era exigido esforço físico; $77 \%$ dos entrevistados não achavam que o seu trabalho era complexo e $71 \%$ dos entrevistados gostavam muito do seu ambiente de trabalho.

Os trabalhadores relataram que sentiam durante a jornada de trabalho: dor de cabeça, cansaço, estresse, desconforto e/ou dor nas costas, no braço, no pescoço, nas mãos, nas pernas e nos pés. Ao tabular os dados, constatou-se que $100 \%$ dos entrevistados sentiam algum desconforto e/ou dor; $64 \%$ dos entrevistados sentiam todos os desconfortos ou dores relacionados na pesquisa; $11 \%$ dos entrevistados sentiam $30 \%$ dos desconfortos ou dores; e $100 \%$ dos entrevistados sentiam cansaço.

\subsection{Diagnóstico}

A partir de vistoria realizada no local, foi verificado que o ambiente físico apresentava diversas deficiências, tais como: o leiaute adotado não favorecia a interação entre os serviços, devido ao confinamento de cada diferente tipo de serviços em salas separadas 


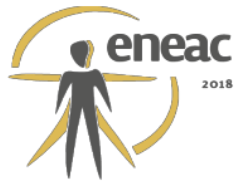

(Figura 6); a iluminação era irregular e insuficiente em alguns locais; o ambiente possuía alto ruído interno, devido ao ruidoso sistema de refrigeração e ao som proveniente da conversação derivada do atendimento (Figura 7); as instalações encontravam-se descobertas, expondo os usuários a riscos de acidentes. O mobiliário não era padronizado e não proporcionava conforto nem funcionalidade. As placas de sinalização interna não cumpriam a função de orientar o deslocamento interno.

Figura 6 (à esquerda) - Sala de atendimento isolada por divisórias Figura 7 (à direita) - Sala de atendimento sem isolamento acústico entre os postos de trabalho
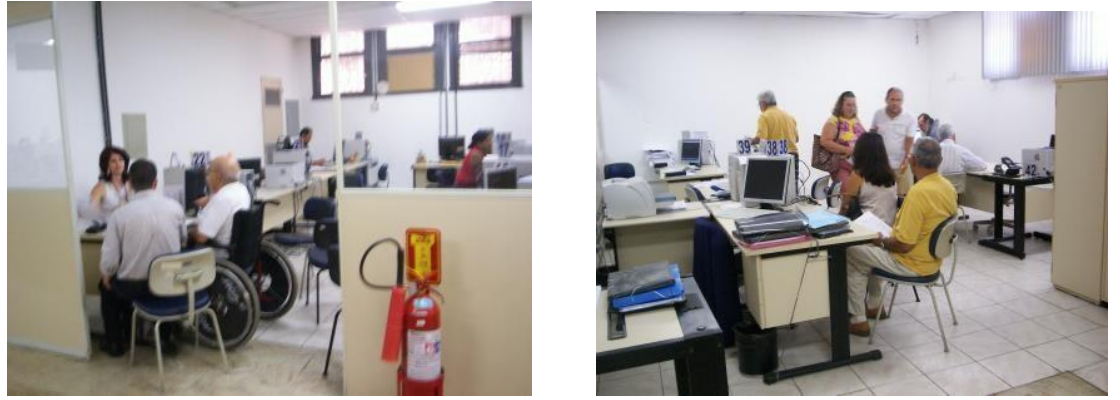

Fonte: Autoras

A maioria das queixas relacionadas à saúde do trabalhador foram dores nos pulsos, nos braços e nos ombros, além de dificuldade de audição relacionada ao ruído ambiente. Segundo o relato de alguns atendentes, o ambiente ruidoso, a grande movimentação de pessoas e a elevada demandas cognitivas devido ao contanto constante com o público, causava-Ihes problemas de esgotamento mental e stress. Os atendentes também se ressentiam da proximidade física com o público durante o atendimento, tanto pela exposição a doenças infectocontagiosas, como pelo risco de sofrerem agressões verbais e físicas. Em relação ao risco no ambiente do trabalho, foram relatados casos diários de agressão física e verbal aos atendentes; por isso, o ambiente possuía sistema de vigilância presencial de forma ostensiva. Segundo os atendentes, os motivos de agressão variavam de insatisfações com o governo pela cobrança de tributos, a descontentamentos pelo tempo de espera para ser atendido, e também por discordância dos procedimentos e deferimentos dos assuntos tratados.

\subsection{Projeto}

Tendo em vista que a finalidade da avaliação ergonômica seria elaborar um projeto arquitetônico para o ambiente construído, as informações coletadas foram traduzidas em ações ergonômicas direcionadas ao ambiente construído. Partido do princípio que as condições físicas do ambiente influenciam no desempenho das atividades, o projeto arquitetônico procurou alinhar o arranjo das atividades e o arranjo dos espaços a fim de contribuir para o desempenho adequado da habitabilidade, satisfação, motivação e conseqüente qualidade de vida no trabalho.

Em relação às demandas do ambiente físico, foi proposto um projeto arquitetônico de reformulação do leiaute do ambiente (Figura 8). 


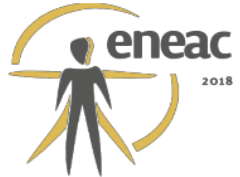

Figura 8 - Proposta de leiaute para o ambiente de atendimento ao público

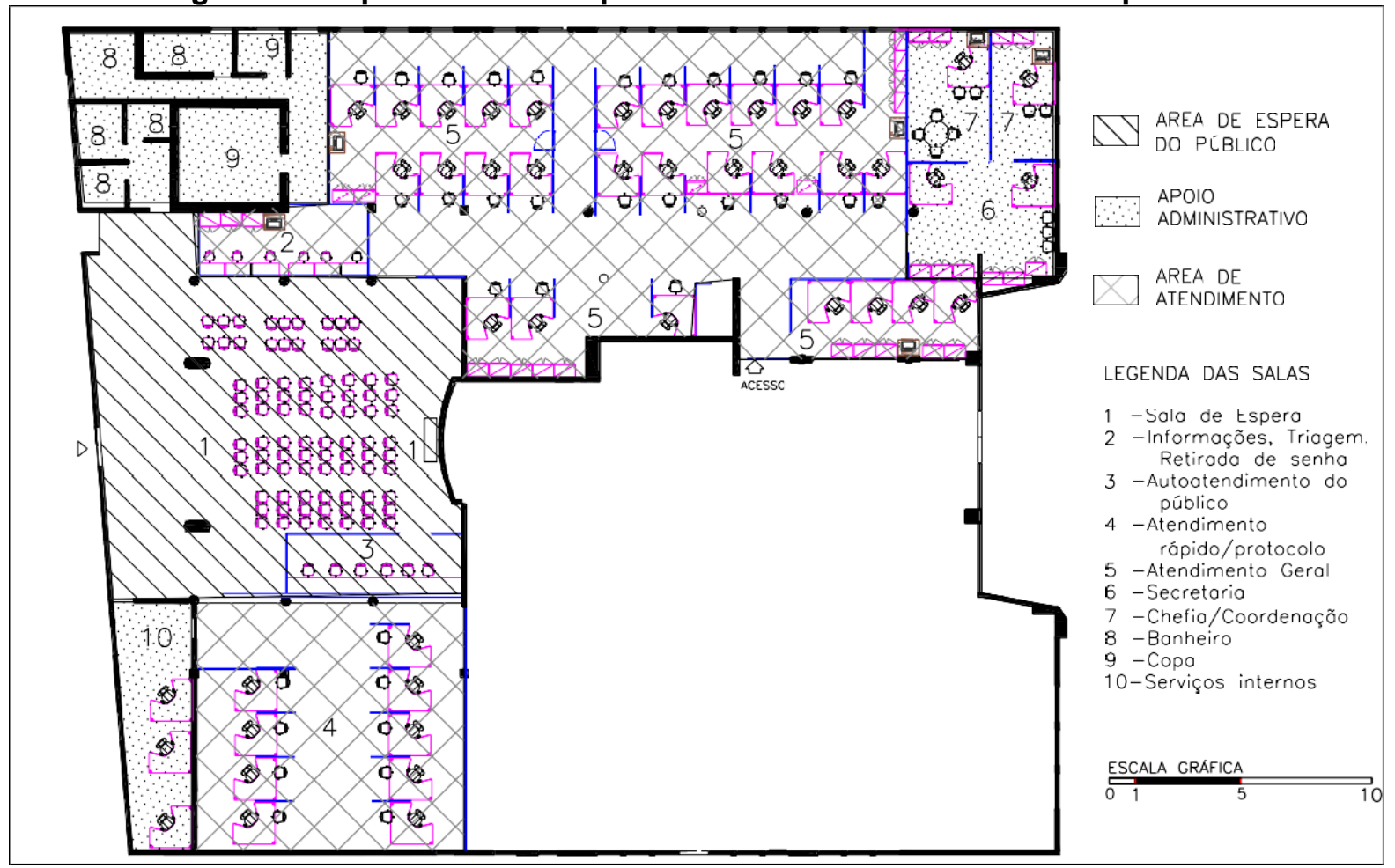

Fonte: Ana Paula Costa

A distribuição dos postos de trabalho procurou seguir a sequencia do sistema de atendimento, de modo a favorecer o desenrolar das ações desenvolvidas pelo público para ser atendido. O projeto buscou padronizar os ambientes de trabalho, agrupando os postos de trabalho, criando ilhas com os grupos de atendimento (Figura 9). Buscou-se integrar o ambiente e facilitar a visualização dos departamentos, sendo abolida a divisão de salas para cada tipo de atendimento (Figura 10). O setor de informações e triagem passou a se localizar próximo ao setor de atendimento, de modo a facilitar a interação entre os serviços.

Figura 9 (à direita) - Postos de trabalho agrupados em ilhas de serviços Figura 10 (à esquerda) - Posto de trabalho individualizado com septo vertical.

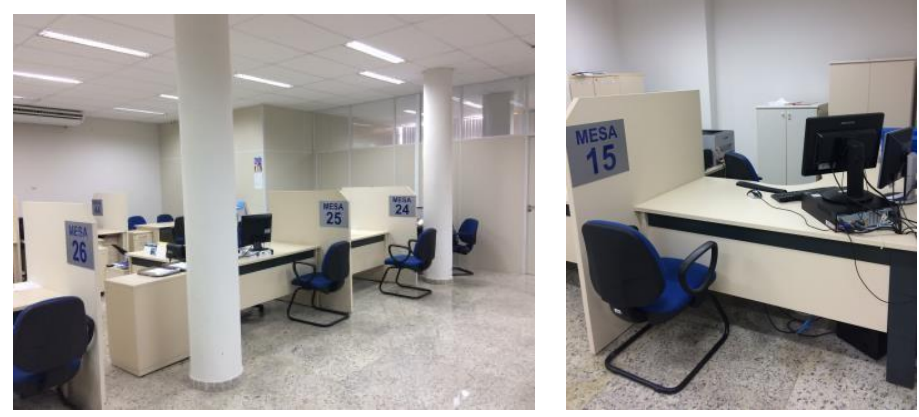

Fonte: Ana Paula Costa

Os postos de trabalho foram dimensionados e especificados de maneira a acomodar confortavelmente 0 atendente e o público. O mobiliário foi padronizado e especificado seguindo parâmetros ergonômicos de conforto e funcionalidade. A maior profundidade da superfície de trabalho proporcionou mais espaço para dispor o material de trabalho e 


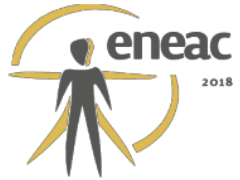

distanciou o contato físico entre o atendente e o público. Também foram previstos septos verticais entre os postos de trabalho, de modo a proporcionar melhor isolamento acústico e visual entre as estações de trabalho.

A fim de informar e orientar o deslocamento do público dentro do ambiente, um sistema de sinalização interna foi implantado.

No intuito de minimizar os incômodos causados pelos ruídos e melhorar o desempenho acústico do ambiente, o sistema de refrigeração foi modernizado, e forros acústicos foram utilizados. As instalações elétricas e lógicas foram ordenadas e embutidas. A iluminação do ambiente foi regularizada a partir de projeto luminotécnico.

Em relação às medidas organizacionais, foi implantado o sistema de marcação prévia do atendimento, fazendo com que o público apenas se deslocasse à repartição pública na hora determinada para o atendimento, evitando enfrentar filas e permanecer por tempo indeterminado na sala de espera (Figura 11). Também foram implantadas postos de autoatendimento, supervisionados e orientados por funcionários da repartição publica (Figura 12).

Figura 11 (à esquerda) - Área de espera de atendimento, com o ambiente de triagem ao fundo. Figura 12 (à direita) - área de atendimento com sala de autoatendimento (à direita)

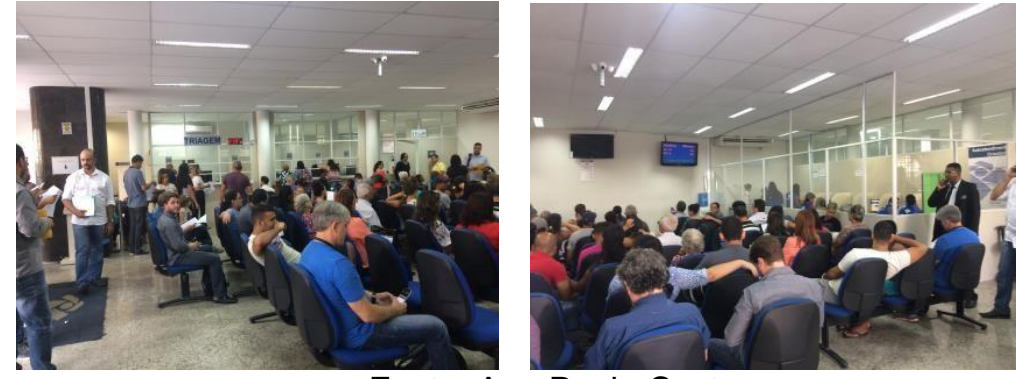

Fonte: Ana Paula Costa

\subsection{Fase de Implantação do Processo}

Nessa intervenção ergonômica, as ações para adequação do ambiente de atendimento ao público iniciaram no ano de 2006. Inicialmente foi elaborado o projeto de reforma do ambiente físico e foram implantadas algumas intervenções no leiaute. No ano de 2011 foram iniciados os procedimentos para realização das obras e aquisição de mobiliário, que foram concluídas no ano de 2017, e o local de atendimento ao público entrou em pleno funcionamento.

\section{DISCUSSÃO}

A necessidade de adequar os ambientes construídos às necessidades humanas impõe desafios constantes aos projetistas, exigindo das organizações um comportamento flexível às mudanças e uma predisposição para a quebra de paradigmas proveniente das concepções impostas pelas convenções organizacionais. Novas formas de conceber e organizar o trabalho muitas vezes requerem novos espaços de trabalho, nos quais as formas de trabalho tornam-se aspectos de relevante importância sobre a motivação e a produtividade do trabalhador.

Através desse estudo procurou-se enfatizar uma visão sistêmica sobre o ambiente de trabalho, onde o cenário físico fosse capaz de reunir soluções integradas voltadas à melhoria das condições de trabalho e ao conforto e bem-estar dos seus funcionários. Neste 


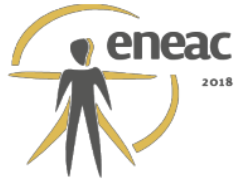

sentido, a ergonomia configurou-se numa importante ferramenta, consolidando as ações direcionadas para a melhoria da qualidade de vida.

O uso da AMT permitiu a identificação de demandas ergonômicas de usuários em ambiente construído, sendo geradas demandas ergonômicas que englobam as diversas dimensões do trabalho. O método proporcionou informações adicionais que auxiliaram na solução de problemas de ordem conjuntural. A AMT mostrou ser uma ferramenta que facilitou a exteriorização da percepção do usuário, levando à identificação de fatores que passariam despercebidos em levantamento de dados para elaboração do programa de necessidades de um projeto arquitetônico.

\section{REFERÊNCIAS BIBLIOGRÁFICAS}

ASSIS, Mônica; BATISTA, Raquel Meireles; ZERBETTO, Cristiane Affonso de Almeida; "Análise Macroergonômica do Trabalho no Setor Administrativo de uma Empresa de Confecção", p. 811-822. In: Anais do 15ํㅡㄹ Ergodesign \& Usihc [=Blucher Design Proceedings, vol. 2, no 1. São Paulo: Blucher, 2015. ISSN 2318-6968, DOI 10.5151/15 ergodesign-45-E149

BRASIL. Secretaria da Receita Federal (SRF). Portaria SRF no 1.917, de 25 de outubro de 1993. Cria o Programa de Melhoria do Atendimento ao Contribuinte, no âmbito da SRF. Disponível em:<http://sijut.fazenda.gov.br/netacgi/nph-brs?s7=@CITX\%3D10\&s10=\&s11=\&SECT1=SIATW1\&d= SIAT\&p=1\&u=..\%2FPesquisa. $h t m \& r=0 \& f=S \& l=20 \& s 1=\% 27 \mathrm{P} \% 27 \& s 2=1917 \& s 3=S R F \& s 4=\& s 5=\& s 8 \&$ $\mathrm{s} 6=\& s 9=>$. Acesso em: 15 jul. 2011.

CORBARI, Jackson Aluir. Avaliação da Implantação do Centro de Atendimento ao Contribuinte (CAC) em uma Unidade Aduaneira da Receita Federal do Brasil. Revista da Receita Federal: estudos tributários e aduaneiros. v. 1, n.2 (2015). ISSN: 2359-4284. Disponível em http://www. revistadareceitafederal.receita.fazenda.gov.br/index.php/revistadareceitafedera/article/view/6/26.

Acessado em 22/10/2018

FERREIRA, Mario César. Serviço de Atendimento ao Público: 0 que é? Como analisá-lo?. Esboço de uma Abordagem Teórico-Metodológica em Ergonomia. Revista Multitemas, ㄲo16, maio, 2000, pp. 128-144, Campo Grande-MS, UCDB. Disponível em: http://www.ergopublic.com.br/ arquivos/1359566570.05-arquivo.pdf. Acesso em: 28 de janeiro de 2018

; MENDES, Ana Magnólia. "Só de pensar em vir trabalhar, já fico de mau humor": atividade de atendimento ao público e prazer-sofrimento no trabalho. Estudos de Psicologia, 6 (1), páginas 93-104. 2001

GUIMARÃES, Lia Buarque de Macedo. Introdução à ergonomia. In: Guimarães, Lia Buarque de Macedo. Ergonomia de Processo, volume 1. Porto Alegre, FEENG/UFRGS. 2004

Análise Macroergonômica do Trabalho - AMT. Modelo de implementação e avaliação de um programa de ergonomia da empresa. 2002. Artigo não publicado. Disponível em http://www.ergonomia.ufpr.br/ indicador AMT.pdf. Acesso em 28/01/2018

Abordagem Ergonômica: o Método Macro. In: Guimarães, Lia Buarque de Macedo. Ergonomia de Processo, volume 1. Porto Alegre: UFRGS/PPGEP. 1999

Costelha, Marcelo Fabiano. Macroergonomia. In: Guimarães, Lia Buarque de Macedo. Ergonomia de Processo, volume 2. Porto Alegre, FEENG/UFRGS. 2006

IEA. The International Ergonomics Association. Disponível em: http://www.iea.cc/whats/index.html. Acessado em 25/01/2018

IIDA, Itiro. Ergonomia: projeto e produção. 2ª edição - São Paulo: Blucher, 2005 